\title{
¿OTRA SOBERANÍA O LA CULTURA DE SIEMPRE?
}

\author{
André Menard 1
}

\begin{abstract}
El artículo plantea un tema de alto interés histórico-antropológico como de vigencia política, a saber una discusión desde una perspectiva histórica y cultural de la noción de soberanía en el contexto mapuche. En este marco considero que lo más valioso del texto es la discusión que abre en torno a formas no occidentales o modernas de entender la noción de Estado y de soberanía, así como la identificación de las formas contradictorias en que estas categorías se oponían (asimilacionaista/ conglomerativa y survivalista, o entre lógica vertical/ horizontal, etc.) en la relación mapuche/española.

Dicho lo anterior creo que la discusión se limita -como dice el título- a una reflexión con demasiados juicios de carácter general y no suficiente análisis de datos históricos y etnográficos que los justifiquen o que permitan sostener la hipótesis del autor, que en las escalas históricas que implica. Esta supone la continuidad no solo de una forma de entender o de ejercer una soberanía mapuche sino que de los contenidos culturales que le darían su consistencia. El problema es que para postularla el autor se funda en los sin duda ricos e importantes materiales y teorías que ha ido trabajando durante cuarenta años, pero que, como se ve en el artículo, se focalizan preferentemente en datos y estudios del periodo anterior al siglo XVIII ${ }^{1}$, lo que le hace descuidar, sino directamente ignorar el material documental de los siglos posteriores así como a autores y trabajos más o menos recientes referidos directamente a la problemática abordada (que en el texto se concentran básicamente en José Bengoa y José Mariman). Pienso por ejemplo en los trabajos de los cacicazgos del Puelmapu en el siglo XIX o de los movimientos mapuche en el siglo XX y principios del XXI (aquí podemos nombrar entre otros los trabajos de Julio Vezub, Ingrid de Jong, Jorge Pavez, Rolf Foerster, José Ancan, Pablo Mariman o Fernando Pairican), los que además tienen el interés
\end{abstract}

de plantear el problema de la soberanía mapuche (así como su evolución histórica, su relación con la soberanía estatal imperial o republicana, o su serie de declinaciones en categorías como independencia, autonomía o autodeterminación) no solo como una categoría analítica enunciada por el investigador, sino que como una cuestión tratada explícitamente por los actores y líderes mapuche en sus distintos contextos históricos.

En cuanto al enfoque mismo, se abusa de un uso demasiado generalizador de la categoría "mapuche" y a fortiori de la categoría "pueblos indígenas", lo que tiene tres efectos negativos: primero, se borra de un plumazo la complejidad y heterogeneidad histórica y espacial de las formas que han tomado los enunciados de mapuchidad (y de indigeneidad) a lo largo de la historia. Segundo, se naturaliza la categoría de pueblo indígena como si fuera un sujeto dotado de ciertas propiedades culturales objetivas (horizontalidad política, respeto por la naturaleza, carácter espiritual o religioso) sin considerar el que su existencia como sujeto (jurídico-político) de carácter explícitamente global tiene una historia específica e inseparable de la evolución de la condición colonial y del derecho internacional a lo largo del siglo $\mathrm{XX}^{2}$. Y tercero, lo anterior hace que las reflexiones y observaciones adquieran un carácter más normativo que descriptivo a la hora de hablar de unas formas mapuche de la soberanía ${ }^{3}$.

En este marco la discusión por las otras formas de soberanía termina reducida a la reinstalación de un culturalismo filoindianista de los más clásicos, lo que más allá de las simpatías políticas que uno pueda tener por estas posturas, resulta desilusionante a la hora de tratar la importante pregunta por las formas que puede tomar una soberanía sin Estado. $Y$ es que en lugar de exponer una forma realmente alternativa, una forma mapuche de enfrentar el poder, la política y el Estado, el autor termina aplanando la

1 Departamento de Antropología, Facultad de Ciencias Sociales, Universidad de Chile, Santiago. peromenard@gmail.com 
cuestión de lo político -como trabajo de enunciación y negociación de conflictos y proyectos comunes-a un trabajo de perpetuación de marcadores culturales, como si la idea de "cultura" (que se plantea como centro mismo que sostenía la guerra y la resistencia mapuche, Dillehay 2016:696 en este número) hubiera tenido un valor por sí misma en tanto objeto político desde tiempos ancestrales. De esta forma surge por ejemplo el problema de no considerar la contingencia histórica que determina que se utilice en un momento y no en otro el término "cultura" (o "cosmovisión" o "epistemologías" o más actualmente "ontologías") como objeto de reivindicación política, y lo que es más grave, es que si se afirma la continuidad de este tipo de reivindicación, el autor debería entregar datos históricos que permitan sostener esta continuidad, mostrando a qué otros términos el término actual de cultura podría haber correspondido en los discursos políticos mapuche a lo largo de la historia. En este sentido, lo mismo se puede decir de la noción de admapu, la que solo se enuncia sin ofrecer ninguna perspectiva histórica respecto de su origen, permanencia, evolución o transformación, lo que hubiera aportado un esfuerzo argumental necesario para sostener la hipótesis de su ancestralidad.

De esta forma para criticar la tesis de la etnogénesis mapuche mediante el postulado de esta continuidad de ciertos contenidos culturales, y sobre todo de una voluntad de perpetuación de los mismos, hubiera sido necesario entregar datos y de paso definir cuáles serían los límites, los contenidos y/o las formas que permitirían identificar una Araucanian ethnicity (Dillehay 2016:695 en este número) a lo largo de los siglos. Y el problema es que el autor cae sistemáticamente en la tautología de señalar como propiedad de esta Auraucanian ethnicity (que debemos suponer como una serie de rasgos culturales), un tipo de política mapuche definida por la búsqueda de una perpetuación de estos rasgos culturales mapuche.

De esta forma se postula una política culturalista, de tonalidad "patriótica" (y que la antigua antropología hubiera asociado a cierta forma de nativismo), por la cual la soberanía mapuche se concentraría en la perpetuación de ciertos marcadores étnicos (y no de otros que el autor identifica como excepciones sin explicar el porqué, como los famosísimos ejemplos del trigo y el caballo, a los que se podrían agregar otros más políticamente complejos como los uniformes militares o los nombres propios, sin hablar de tecnologías como la escritura alfabética), lo que ya está suponiendo en la mentalidad y la práctica de ese mapuche homogéneamente caracterizado, una idea de cultura propia de una antropología de cierto momento del siglo XX. Se plantea así una idea bastante conservadora de la cultura (o en otros términos propias de una "ontología" occidental, moderna y naturalista de cultura) como un inventario de rasgos culturales que pueden ser objeto de protección política, lo que en el peor de los casos nos recuerda la figura del "mapuchómetro" como dispositivo normativo con el cual medir grados de fidelidad a una tradición cultural unívoca (que es lo que a su manera aplica Sergio Villalobos en sentido inverso para demostrar la pérdida de mapuchidad de los mapuche contemporáneos).

De hecho, se podría decir de su tesis "etnomórfica" sobre la continuidad cultural de la soberanía mapuche, algo análogo a lo que en otros trabajos he dicho de la variable caníbal con que Guillaume Boccara construye su tesis de la etnogénesis mapuche: que confunde el plano de enunciación del investigador con el de los actores mapuche. En el caso de la tesis caníbal levantada por Boccara esto se traduce en la confusión en un mismo plano de canibalizaciones como la del trigo o el caballo con la de elementos como nombres propios, uniformes o cautivos. Y digo confusión pues si en el primer caso la incorporación de estos elementos no dejó huellas explícitas del gesto de incorporación misma, haciendo de estos elementos rasgos culturales percibidos como mapuche, en el caso de los segundos, el gesto mismo de incorporación de un elemento ajeno era puesto en valor y visibilizado por los mismos actores mapuche, transformándolos en signos de prestigio y autoridad. Confusión entonces entre la lectura de un registro de canibalización realizada por parte del investigador en ciertos archivos historiográficos y sus registros, y lectura de un registro de canibalización realizada por parte de ciertos actores mapuche en el marco de lo que he llamado formas mapuche del archivo y del registro. En el caso del texto de Dillehay, y esto nos lleva al problema anunciado al inicio de este comentario, se podría decir algo parecido en la medida en que no sabemos si la noción de soberanía como trabajo de conservación de esos rasgos que el autor supone indicadores de autenticidad cultural (esas everyday routines como rituals, activities, decisions, customs, and policies que aquí solo podemos imaginar) también lo han 
sido para una diversidad de actores mapuche, a lo largo de una historia de varios siglos y de una enorme diversidad de contextos, al momento de enunciar explícitamente el problema político de su soberanía. Y con esto no quiero decir que esta variable cultural (que podemos ampliar a nociones quizás análogas, pero en absoluto equivalentes, como costumbres, tradiciones o incluso el admapu) no haya sido utilizada como argumento político, sino que habría que ver en qué contextos y por qué actores específicos lo ha sido, antes de volverla condición normativa de toda forma de soberanía en su versión mapuche, por no decir indígena.

En este sentido, y quizás lo más problemático, es que falta un verdadero trabajo de estudio y revisión tanto de la evolución histórica como de la presencia actual de enunciados autonomistas mapuche o referidos a una forma de soberanía política. En este sentido los únicos dos ejemplos de persistencia de esta conciencia soberana mapuche son una referencia a la muy marginal celebración de los 150 años de la proclamación del Reino de Araucanía y Patagonia, dato al que no se le añade ningún antecedente que lo sitúe en la historia y en el contexto actual del movimiento y las demandas mapuche (como que el recientemente fallecido heredero era un funcionario del ministerio de defensa francés que por lo demás ha sido cuestionado en la legitimidad nobiliaria de su pretensión al título, que sus redes mapuche se limitaban a escasos integrantes de organizaciones en Inglaterra y Holanda, etc.), y el segundo ejemplo se limita a afirmar que recently, upon 2014 election of President Michelle Bachelet, Mapuche leaders once again called for sovereign indigenous nation within Chilean state (Dillehay 2016:698 en este número). ¿Qué dirigentes?, ¿en qué contexto?, ¿qué proyecto exactamente proponían?, ¿cómo se relacionaban esas demandas con lo afirmado anteriormente acerca de las formas supuestamente mapuche del poder y la soberanía?

Hubiera sido necesario al menos señalar la existencia de una tradición de discursos de la soberanía política mapuche por parte de líderes e intelectuales mapuche, como por ejemplo las cartas de mediados del siglo XIX escritas por Mangil Wenu en que señala al río Biobío como frontera del "Mapu" con Chile y su referencia a los tratados de 1793 como base de este límite, o las declaraciones de Manuel Aburto y la Federación Araucana en los años treinta llamando a la creación de una República Indígena federada a Chile, o los más recientes trabajos del abogado José Lincoqueo y su reivindicación de los tratados como recursos del derecho internacional para sostener la autonomía mapuche. Y esto por nombrar solo algunos pocos ejemplos ${ }^{4}$.

Y si nos centramos en la situación actual, esta superficialidad histórico-política en el tratamiento de los discursos autonómicos mapuche se vuelve aun más evidente al final del texto cuando se postula que actualmente solo hay dos propuestas de soberanía o self-governance mapuche: aquella que plantea espacios de autogobierno a nivel local y dentro del territorio chileno, y la que plantea la creación de un Estado mapuche diferente al chileno. En su extrema generalidad, esta afirmación no aporta mucha información, pues una cosa es el proyecto de la CAM que efectivamente busca una forma de autonomía local, en espacios exclusivamente rurales y dentro de un marco altamente culturalista. Otra cosa es el proyecto de las identidades territoriales. Otro es el de los proyectos a nivel municipal como en Tirúa o Galvarino. Otro fue el levantado en la década de 1990 por el Consejo de Todas las Tierras que proponía cuotas indígenas en el Parlamento. Otro es el de generar un Parlamento indígena. Otro el de Wallmapuwen (o el del mismo José Mariman) por ejemplo que se basa en un proyecto regionalista orientado a entregar mayores cuotas de autonomía a las regiones en el marco del Estado chileno...

En síntesis, el texto plantea el desafío, a mi parecer interesante y necesario de explorar unas formas otras o no etnocéntricas de pensar la soberanía. Sin embargo, me parece problemático hacerlo recurriendo a un uso que podríamos llamar etnocéntrico del concepto de cultura, y por qué no, del de etnia. Y digo etnocéntrico en el sentido de un uso irreflexivo respecto de las condiciones históricas y contingentes en que estos conceptos han surgido y circulado. De ahí que más allá de las reflexiones del autor y de sus convicciones respecto del valor de las reivindicaciones culturales como forma indígena de la política, el trabajo no va mucho más allá de los supuestos que guían muchas de las actuales políticas de gestión multicultural de las diferencias humanas y su pulsión por marcar reivindicaciones y luchas políticas de pueblos indígenas con un "suplemento de alteridad", alteridad que al parecer solo puede ser traducida al lenguaje de nuestra modernidad secularizada, como un suplemento de espiritualidad. Y con esto no quiero decir que las políticas indígenas no impliquen una dimensión mágica, religiosa o 
espiritual, sino que por el contrario, que toda forma de la política, incluida la nuestra, la implica. La cuestión es cómo dar cuenta de la diferencia entre estas formas de la política y de su magia (o de la magia y su política) sin despolitizarla, es decir, sin ordenarla etnocéntrica o colonialmente, reservándole la espiritualidad a los indígenas y guardándonos la política para nosotros.

\section{Referencias Citadas}

Dillehay, T.D. 2007. Monumentos, Imperios y Resistencia en los Andes. El Sistema de Gobierno Mapuche y las Narrativas Rituales. Quillca, San Pedro de Atacama.
Dillehay, T.D. 2016. Reflections on Araucanian/Mapuche resilience, independence, and ethnomorphosis in Colonial (and present-day) Chile. Chungara Revista de Antropología Chilena 48:691-702.

\section{Notas}

1 Datos que en otros lugares de su obra son correlacionados con la data etnográfica que ha logrado recoger en terreno (cf. Dillehay, T. 2007 Monumentos, imperios y resistencia en los Andes. El sistema de gobierno mapuche y las narrativas rituales (2007), Quillca, San Pedro de Atacama).

2 Y que por lo demás al estar dotado de esas tres propiedades (horizontalidad política, ecologismo y espiritualidad) funcionan sospechosamente como la proyección ética, romántica e invertida de las cualidades por las cuales la modernidad se define (jerarquía estatal, oposición a la naturaleza, secularización).

3 Y el problema es que esta generalización de las cualidades de lo mapuche puede implicar sesgos delicados, como cuando se habla de ciertas formas mapuche de la política centradas en ciertas propiedades culturales y por otro se cita a autores mapuche como José Mariman que tienen explícitas diferencias respecto de una definición cultural (cosmovisional) de los enunciados políticos mapuche, y se apoyan en concepciones más modernas de la autonomía política (inspiradas por ejemplo de los independentismos vasco o catalán, o de las demandas de descentralización regionalista).

4 Si ampliamos el problema a la cuestión de la representación política a nivel de la nación chilena, el artículo muestra igualmente una miopía o al menos cierta falta de rigor historiográfico cuando por ejemplo se señala que solo hay un congresista mapuche. ¿A quién se refiere? ¿A Huenchumilla que fue diputado hace 20 años? ¿Por qué no considera la historia de la importante participación mapuche en el Congreso a lo largo del siglo XX? 